\title{
Strategic Management and Branding Panacea for Surviving in Volatile Environments: Case of Zimbabwe Tourism Industry
}

\author{
Farai Chigora \\ Faculty of Commerce, Catholic University of Zimbabwe, Zimbabwe \\ E-mail: fchigora@yahoo.com Tel: 263-772-886-871 \\ Promise Zvavahera (Corresponding author) \\ National University of Science and Technology, Zimbabwe \\ E-mail: promisezvavahera59@gmail.com Tel: 263-773-471-703
}

Received: June 23, 2015 Accepted: July 25, 2015 Published: November 9, 2015

doi:10.5296/bmh.v3i2.8543ＵRL: http://dx.doi.org/10.5296/bmh.v3i2.8543

\begin{abstract}
The Zimbabwe tourism destination has been rebranded three times between the years 1980 and 2011. It started with the brand name "Discover Zimbabwe" after independence in 1980, to "Africa Paradise" in 1996, then "Zimbabwe a World of Wonders" in 2011. The change was done as an effort to strategically position the country's tourism destination through an attractive brand. The first two brands failed to change the perceptions of tourists towards Zimbabwe. This study sought to explore strategic factors that might have affected the tourism destination. The research applied both quantitative and qualitative approaches to extract data. The results showed that the majority of tourism players in Zimbabwe used the branding concept separately from strategic management. The study discovered that the failure of the tourism industry is attributed to the failure by the authorities to strategically consult key stakeholders in the formulation of the brand. The study therefore, recommended a brand-strategic model suitable for tourism destinations emphasising on combining branding and strategic management.
\end{abstract}

Keywords: branding, strategic management, stakeholders, tourism, destination 


\section{Introduction}

Zimbabwe tourism brand has faced various negative slams because of its socio-economic and political state over the years (Ndlovu \& Heath, 2013). These events have destroyed the brand's repute intensified by negative media publicity campaigns portraying the destination as not safe for any visits. Destination marketing organisations in Zimbabwe led by Zimbabwe Tourism Authority have therefore, tried to react to the tarnished image through various promotions focusing on rebranding as an exceptional ingredient for face lift it. This has seen the country changing its brand for three times between year 1980 and 2011. The country started with the "Discover Zimbabwe" brand soon after its independence in 1980 to "Africa's Paradise" in 1996 and "World of Wonders" in 2011 (Chibaya, 2013). These efforts to rebrand unfortunately have not improved visits over the years. This has been mainly attributed to internal factors such as the hyper-inflation between year 2000 and 2009, natural disasters such as droughts, local political parties' fights, diseases such as cholera and typhoid. The quality of the brand has reflected such negative associations to an extent of shunning the tourists away. However, from a stakeholder analysis point of view, branding in a destination can be a single means to many others. This is because a tourism destination is an amalgam of many players who are both directly or indirectly related to the industry. It depicts that there is no single fit jacket to survive is volatile environments. Strategic management might be used as holistic tool that encompass every pertinent stakeholder in a tourism destination to improve the Zimbabwean tourism brand. Therefore, there was a need to assess the relationship between strategic management and tourism branding in order to find the best model for surviving in volatile environments.

\section{Problem Statement}

The first tourism brand "Discover Zimbabwe" which failed to distinguish the country's tourism destination with a unique identity since the same theme was being used in other destinations. It was formulated in hasty as the country wanted to position itself and enhance identity just after independence as reflected by the change in the name from Rhodesia to Zimbabwe as a first brand. However, it is said that the brand "Discover Africa" did not involve stakeholders in its formulation and implementation and that is the reason why it failed. Implementation is the outcome and materialisation of an effectively formulated strategy (Raes et al., 2011). Zimbabwe Tourism Authority therefore, rebranded after its inception in 1996 and at this juncture it was considered to have involved needed consultation and stakeholders in its implementation. However, the brand failed to get a millage in terms of popularity and increased tourists' arrivals. This has been subjected to highly volatile negative socio-economic and political events that transpired in the country. Therefore, it was crucial to analyse if it is a strategic or branding issue that makes the tourism industry in Zimbabwe survive in volatile environments.

\section{Literature Review}

Strategic management is a concept that is directed to spearhead the business to a position that is required by owners and stakeholders. It is the fulfilment of top management dreams that is directly measured by equity. This equity can be seen from improved profitability coupled 
with other factors such as a prime position on the stock market, high brand identity and customers loyalty. The dreams of the business are explained in the form of a vision statement which can be shared amongst owners, stakeholders, employees and the world at large (Alkhafaji, 2003). A vision statement will attract its followers using a mission statement that guides what to be done on a day to day basis. Organisations usually display their visions and missions statements in visible areas like the front offices of their establishments. These statements aim to promote conformity and a culture that adheres to the dreams of the investors. Thus, organisations also display their objectives and values with an intension of instilling a culture that corresponds to the desired vision and mission.

Tourism destinations operate as businesses with a dream to attract more visitors for a profit. The realised economic uplift of tourism businesses have seen many nations resorting to the sector as a strategic tool for development. Also countries have established Government Ministries that monitor and direct tourism in their governments. This has resulted in strategic managers at national level crafting policies that support tourism from various ways. The major policies dominating many tourism destinations in the world are centred on positioning and marketing the destination's tourism activities and sustainable conservation of natural resources.

Destinations however, have resorted to branding as a means of creating identity and positioning on the global market. Brands have dominated all our aspects of life from economic, social, cultural and even religion (Kapferer, 2008). Branding has become an exercise mandated for all Destination Marketing Organisations (DMOs), such that every destination is identified as a brand rather than a country. Zimbabwe is currently positioned as a "World of Wonders". The performance of a tourism brand is measured from the number of visitors who patronise the destination. This means that when there are more tourist arrivals, then the destination's brand is highly performing. However, the brand of a country can be easily tarnished due to various factors such as the political state of the country, economic downfall and civil unrest. On the other hand, issues to do with poor natural resource management are increasingly affecting brands globally.

It is important to appreciate areas of strategy formation that can impact the performance of its implementation (Thomas \& Ambrosini, 2015). This is because formulation of a strategy makes the foundation on which the business is to be directed. Therefore, a strategy is seen to be critical during implementation (Raes et al., 2011). Stakeholders should not be involved at the implementation as it is the final stage but rather on the formulation stage. In order to have an effective strategy there is need to understand the development stage of a strategy (Mintzberg \& Waters, 1985). There is no single definition of branding but it is mainly related to name, symbols and trademarks that are given to products and services so that they can be distinguished from competition on the market (Keller, 2013). A destination, like any product needs to be strategically positioned for it to be identified as a prime place to visit. This means that identification through any of the branding elements should follow the strategic dream of its stakeholders. Management has come to the realisation that the main asset for a business is branding (Kapferer, 2008). Recognition of the branding concept in the field of strategic management is the key driver to success. This is because brands like any strategy can be 


\section{Macrothink}

Business and Management Horizons

ISSN 2326-0297

2015, Vol. 3, No. 2

recognised as conditional assets that take long term planning (Kapferer, 2008). Strategic management involves long term planning that needs proper attention and branding as a strategy need a prolonged and encompassing commitment so as to achieve favourable results. The diagram below shows the stages in brand formulation and positioning.

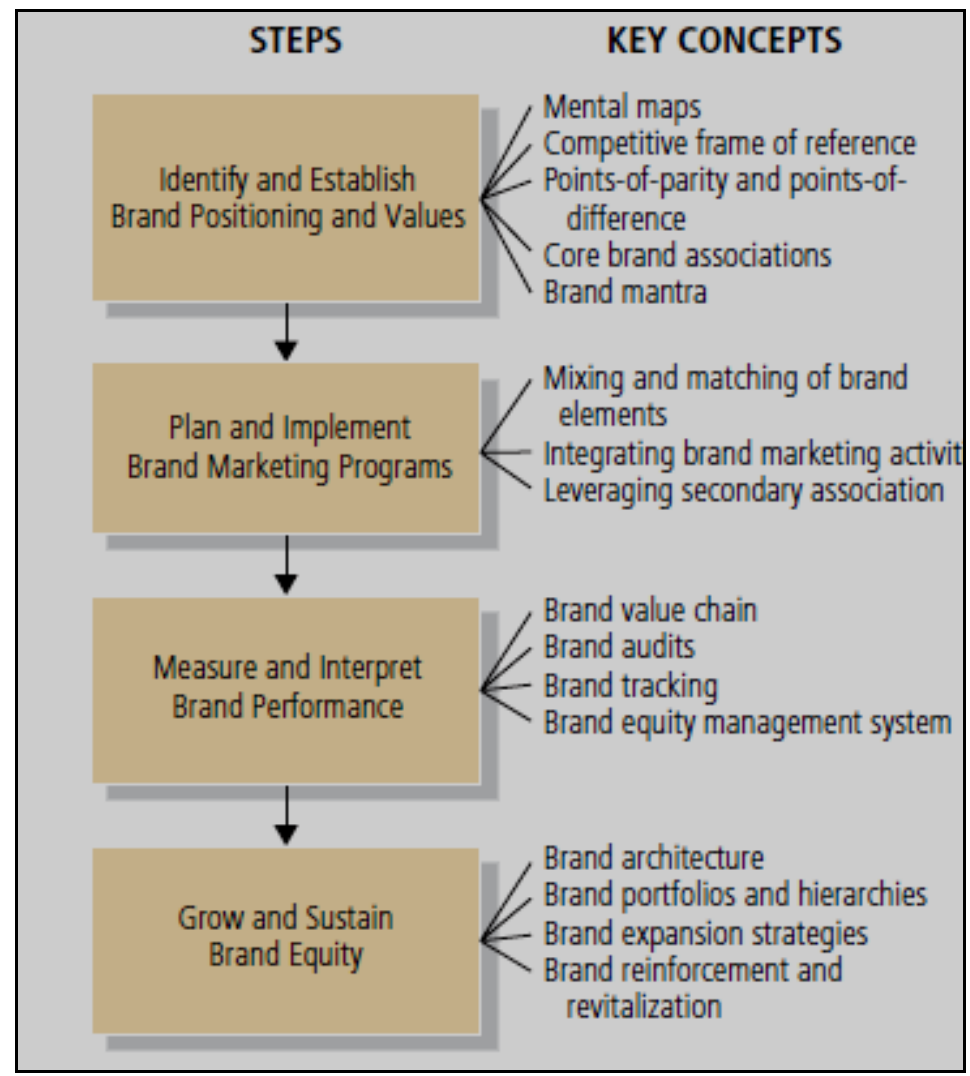

Figure 1. Strategic brand management process

Source: Keller (2013, p.59).

As shown in Figure 1 the strategic brand management process comprises four major stages. These are identifying and establishing brand position and values, planning and implementing brand marketing programs, measuring and interpreting brand performance and growing while sustaining brand equity. Therefore, the end result of an effective strategic brand management is brand equity. This in a tourism destination will enjoy more tourists' inflows accompanied by high revenues. There is need to understand the concept of strategic management and match it with branding so as to craft effective and selling policies that lead to growth in a tourism destination. 


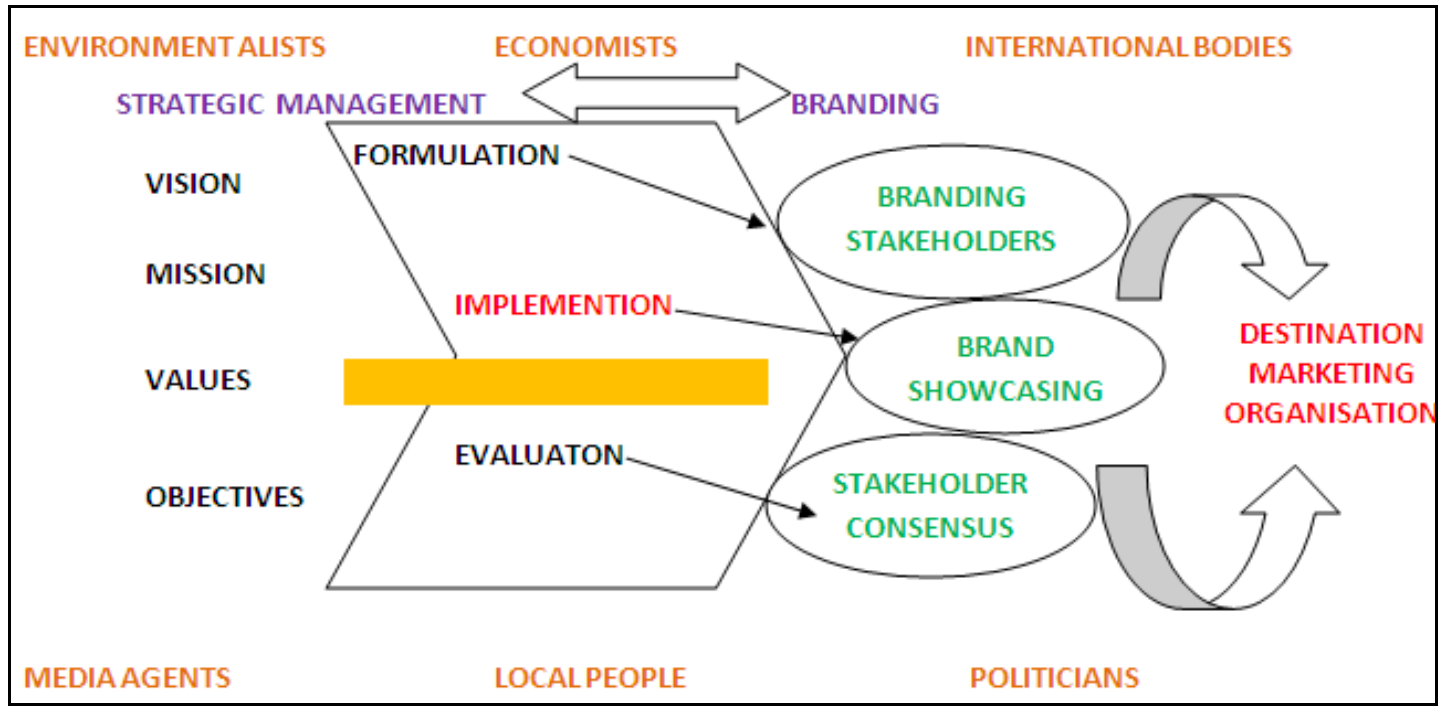

Figure 2. Amalgamated destination strategic-branding model

Source: Research Design (2015).

There is need to appreciate that branding cannot stand on its own, it has to be part of the strategic planning of the whole organisation. Figure 2 shows the proposed model to harness tourism destination branding and strategic management. This entails various destination stakeholders who are environmentalists, economist, international bodies, media agents, local people and politicians. The vision, mission, values and objectives of a destination should help in the formulation, implementation and evaluation of the tourism brand.

\section{Methodology}

The research used both deductive and inductive processes to obtain data from respondents. Therefore, the research design was based on quantitative and qualitative simulations. This was done through administering questionnaires and in-depth interviews in extracting research data from the respondents. The main respondents of the study were randomly selected from the areas of specialty and purposive judgmental sampling was used to identify the most crucial stakeholders with an influence to a country's performance. These included destination marketing organisations, economists, environmentalists, local people, media agents and politicians. The sample of the study was as shown in the table below.

Table 1. Sample of the study

\begin{tabular}{|l|c|c|c|c|c|c|c|}
\hline STAKEHOLDERS & Economists & $\begin{array}{c}\text { Media } \\
\text { Agents }\end{array}$ & Environmentalists & Politicians & $\begin{array}{c}\text { Local } \\
\text { people }\end{array}$ & DMOs & TOTAL \\
\hline POPULATION & 20 & 45 & 30 & 25 & 40 & 50 & $\mathbf{2 1 0}$ \\
\hline
\end{tabular}

Source: Research Survey 2015. 


\section{Macrothink}

Business and Management Horizons

ISSN 2326-0297

2015, Vol. 3, No. 2

The study was based on knowledge of destination branding and strategic management in volatile economies. Zimbabwe was the centre of discussions as it has gone through immense downfalls from a socio-economic and political perspective.

\section{Objective}

The objective of the study was to identify the relationship between branding and strategic management.

\section{Findings and Discussions}

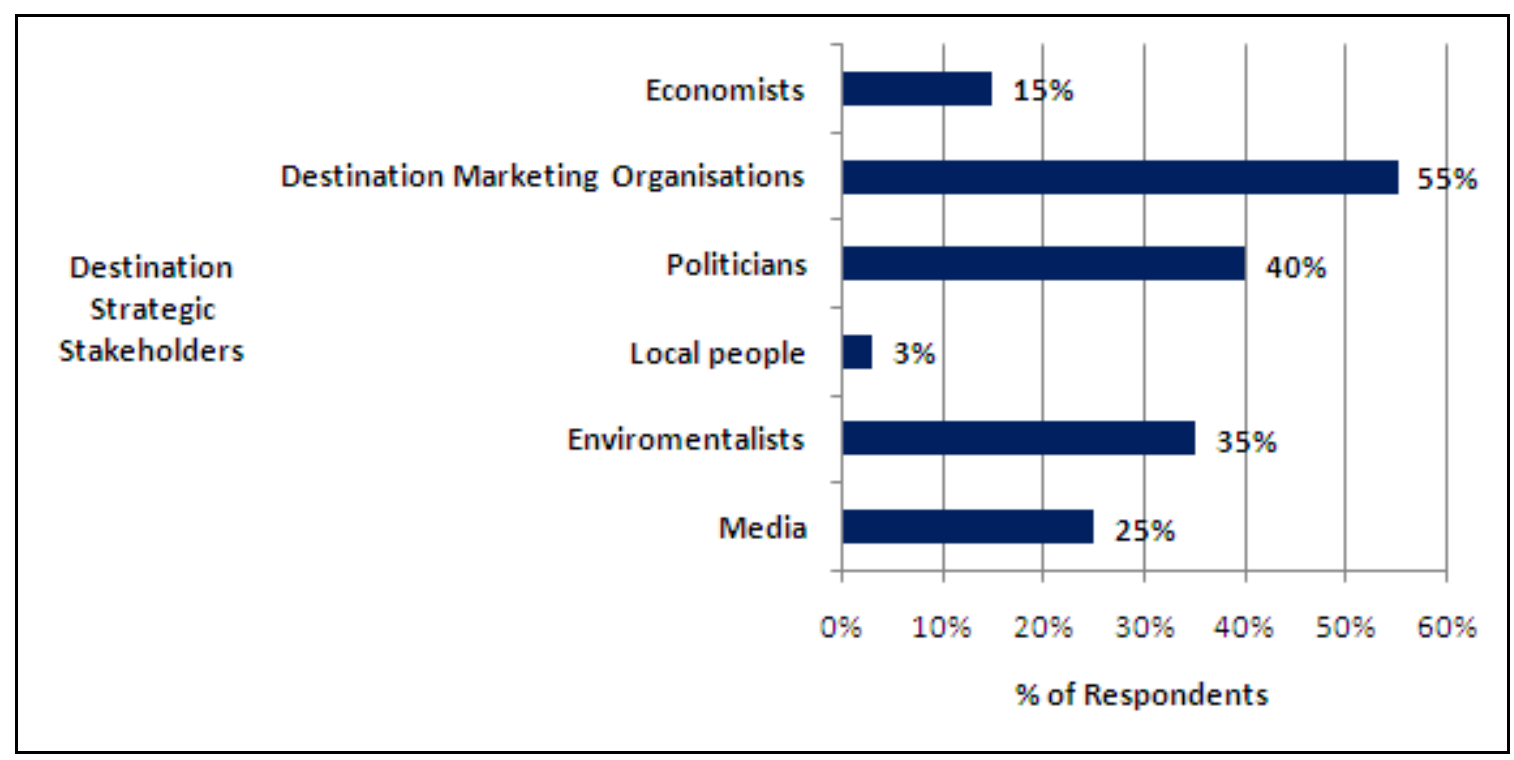

Figure 3. Stakeholders’ participation and branding knowledge

Source: Research Survey (2015).

The findings of the research are as shown in Figure 3. It was revealed that stakeholders had low participative role in brand formulation. There is a smaller percentage (3\%) of local people participation. This is a problem because the general public makes the most significant stakeholders in a country. They have the power to spread positive word of mouth to the world which strengthens the brand of a country. There should be an understanding of what people really do and align it to a strategy (Johnson, Melin, \& Whittington, 2003). Their support to a brand makes them behave in line with its strategic vision. The findings also revealed that destination marketing organisations are the most dominant actors (55\%) in Zimbabwe's tourism brand formulation. This shows that there is limited joint effort of various stakeholders which removes synergy. Another important group is the media which has the power to uplift or tarnish the brand of a country. Their low level participation (25\%) is a cause of major concern. The country's tourism sector has been bombarded by negative media publicity over its socio-economic and policies over the years. This means that media can play a crucial role in rejuvenating the glamour of the tourism brand. Strategic consultation of media agents in brand formulation is highly pertinent since it has the ability to create massive 
positive publicity campaigns. Volatile environments require strategies who are guided by real-time information assimilations (Atuahene-Gima \& Li, 2004). Also environmentalists have a low participation in tourism brand formulation in Zimbabwe. This has a problem because the current paradigm has seen tourists favouring destinations that are ecological friendly through sustainable practices. Therefore, those destinations that have included environmentalists in their strategic brand formulation have managed to attract more tourists through certification programs like the green tourism. Economists are crucial as they can use econometrics models to determine the survival and future gains of a strategy. The findings of this study are line with (Vaara \& Whittington, 2012) who found out that there is a deficiency in understanding the macro issues on the emergence of a strategy. Branding as a strategy should be measured on its life span. This helps strategists to be proactive in addressing any future variables that can negatively affect survival of a brand. Their low level of participation (15\%) also affects the effective implementation of the country's tourism brand. Politicians in a country are crucial in the sense that they formulate policies to run the country. They help in forming government on policy issues. There is need to show the world that there is peace and tranquillity in order to attract attention and uplift the brand image. Involving politicians in brand formulation is crucial and progressive. On average, the findings show that there is low participation of all stakeholders as reflected by their percentages (lower than 50\%) on knowledge and participation in brand formulation. Destination marketing organisations have shown the only dominant part in the tourism brand formulation with $55 \%$ level of knowledge and participation.

Table 1 shows $40 \%$ of the stakeholders announced that the vision of the Zimbabwe tourism brand is not clear with 30\% revealing that they do not even know about the relationship between tourism brand and strategic vision of a destination. Understanding strategy as a practice in its stage of formation is highly important (Sminia \& de Rond, 2012). This therefore, makes it difficult to have a common understanding on the direction required for the branding of the tourism destination. This is because a vision acts as the dream of destination managers to achieve benefits for all stakeholders. Only 30\% have the knowledge and appreciate the strategic vision coming from the tourism brand, which is highly a insignificant percentage for a country that relies on tourism for economic development. The findings also revealed that $95 \%$ of the stakeholders do not know if the Zimbabwe tourism brand matches with the strategic mission of the destination. This is an alarming sign that the strategic position of the brand is not known and can destroy the success of the brand. Failure to appreciate the daily needs in marketing the brand will deter its efforts to attract more tourists' visits. 
Table 2. Stakeholder's responses on strategy—brand management

\begin{tabular}{|l|l|l|l|}
\hline MAIN RESEARCH QUESTIONS FOR ALL STAKEHOLDERS & \% RESPONSE \\
\hline & Yes & No & Not Known \\
\hline 1. The vision for the tourism brand is clear? & $30 \%$ & $40 \%$ & $30 \%$ \\
\hline 2. Does the tourism brand match with its mission? & $5 \%$ & $0 \%$ & $95 \%$ \\
\hline $\begin{array}{l}\text { 3. The tourism brand serves the objectives of the } \\
\text { destination's strategists? }\end{array}$ & $20 \%$ & $5 \%$ & $75 \%$ \\
\hline 4. Values of the country are clearly seen from the brand? & $10 \%$ & $90 \%$ & $0 \%$ \\
\hline
\end{tabular}

Source: Research Survey (2015).

The responses of the stakeholders also reflected $75 \%$ of the stakeholders can not relate the tourism brand to objectives of a destination. It is then difficult to measure the performance of a brand when the objectives are not known. This is because the objectives provide a benchmark to be attained. The absence of clear objectives restricts the destination brand from any positive adjustments in relation to its failure to meet standards set. The values of a destination help in differentiating it from others in the world. The findings show that $90 \%$ of the stakeholders could not clearly identify the values of the tourism destination which therefore makes it difficult to have conformity and uniformity of purpose guided by the expected values of a destination brand. Such issues as the culture of local people, their dressing and language strengthen the values of a brand that will in turn position it on the global tourism market. It is clear from the findings that the concept of strategic management in relation to branding is not known by various stakeholders in Zimbabwe tourism destination.

\section{Recommendations}

Stakeholder involvement is crucial when formulating a brand. Formation of a strategy is shaped by its environment. This helps to strengthen the foundation of the brand emanating from the perspective that different parties have a diversified view and appreciation of the same branding concept. The efforts of various stakeholders from different schools of thought can improve quality and performance of the tourism brand. This is because the synergy of all the stakeholders helps in eliminating faults and overlooks on pertinent issues. Tourism stakeholders should be involved in brand formulation not in the implementation only. Implementation will therefore be a stage brand showcasing. The evaluation of a brand's performance should be based on consensus by all stakeholders. The role of destination marketing organisation spearheaded by Zimbabwe Tourism Authority is to co-ordinate the efforts of all stakeholders so as to improve the position and identity of the tourism brand. It is about strategic-branding management issue.

\section{Conclusion}

Survival in volatile economies takes the effort of strategists to steer their organisations to higher levels by strategically positioning themselves. Those at the strategic level have the 
power to steer the organisation towards success and growth. Volatile economies have been highly positioned as socio-economically and politically unstable. Zimbabwe's economic slump between year 2000 and 2009 destroyed the strategic acumen of various captains of industry and commerce. Those responsible for tourism branding lost their grip of the situation through scattered and disintegrated policies and strategies. The disorientation in Zimbabwe branding arose as a result of treating "branding" as an isolated effort without recognising the strategic call for this drive. Branding and strategic management cannot be separated. The reason for the failure of the Zimbabwean tourism brand can therefore be attributed to destination managers failing to understand the supremacy of a vision, mission, objectives and values of the industry. These elements are crucial when formulating a strategy. They call for maximum stakeholder consultation and once aligned in a holistic manner, brand implementation and evaluation becomes highly objective. Therefore, Zimbabwe tourism destination planners should fuse both branding and strategic management in order to strengthen the tourism brand's awareness, image, perceived quality, loyalty and association. This will even help in overcoming volatility and get maximum equity.

\section{References}

Alkhafaji, A. F. (2003). Strategic Management Formulation, Implementation,and Control in a Dynamic Environment. The Haworth Press.

Atuahene-Gima, K., \& Murray, J. (2004). Antecedents and outcomes of marketing strategy comprehensiveness. Journalof Marketing, 33-46. http://dx.doi.org/10.1509/jmkg.68.4.33.42732

Chibaya, T. (2013). From 'Zimbabwe Africa’s Paradise to Zimbabwe A World of Wonders': Benefits and Challenges of Rebranding Zimbabwe as A Tourist Destination. Developing Country Studies, 13(5), 84-91.

Johnson, G., Melin, L., \& Whittington, R. (2003). Micro strategy and strategizing: towards an activity-based view? Journal of Management Studies, pp. 3-22. http://dx.doi.org/10.1111/1467-6486.t01-2-00002

Kapferer, J.-N. (2008). The new strategic brand management: creating and sustaining brand equity long-term. United Kingdom: British Library Cataloguing-in-Publication Data.

Keller, K. L. (2013). Strategic management: building, measuring and managing brand equity (4th ed.). England: Pearson Education Limited.

Mintzberg, H., \& Waters, J. A. (1985). Of strategies, deliberateand emergent. Strategic Management Journal, pp. 257-272. http://dx.doi.org/10.1002/smj.4250060306

Ndlovu, J., \& Heath, E. (2013). Re-branding of Zimbabwe to enhance sustainable tourism development: Panacea or Villain. Academic Journals, 1(12), 947-955.

Raes, A. M. L., Heijltjes, M., Glunk, U., \& Roe, R. (2011). The interface of the top team and middle managers: a process model. Academy of Management Review, pp. 102-126. 


\section{Mll Macrothink}

Business and Management Horizons

ISSN 2326-0297 2015, Vol. 3, No. 2

Sminia, H., \& de Rond, M. (2012). Context and action in the transformation of strategy scholarships.

Journal of

Management,

pp.

1329-1349.

http://dx.doi.org/10.1111/j.1467-6486.2012.01059.x

Thomas, L., \& Ambrosini, V. (2015). Materializing Strategy: The Role of Comprehensiveness and Management Controls in Strategy Formation in Volatile Environments. British Journal of Management, 26, 105-124. http://dx.doi.org/10.1111/1467-8551.12075

Vaara, E., \& Whittington, R. (2012). Strategy-as-practice: taking social practices seriously. Academy of Management Annals, pp. 285-336. http://dx.doi.org/10.1080/19416520.2012.672039

\section{Copyright Disclaimer}

Copyright for this article is retained by the author(s), with first publication rights granted to the journal.

This is an open-access article distributed under the terms and conditions of the Creative Commons Attribution license (http://creativecommons.org/licenses/by/3.0/). 